\title{
Bogotá: evolución urbana, socioeconómica y ambiental entre 1920 y $2010^{1}$
}

\author{
Bogota: Urban, Socioeconomic and Environmental Evolution \\ between 1920 and 2010
}

Luis Gabriel Duquino Rojas ${ }^{2}$

\section{Resumen}

El objetivo de la investigación fue la revisión de las relaciones existentes entre la evolución urbana y la degradación ambiental urbana, que se han dado en el marco de los procesos de imposición de estructuras ideológicas de dominación, en los modos de vida y acción de la sociedad. Se utilizó una metodología cualitativa donde se privilegió el estudio de las relaciones entre las partes constituyentes del objeto de investigación y el carácter dialéctico de la realidad examinada. Como resultado se obtuvo un análisis geohistórico que informa de los procesos de explotación que han degradado el ambiente urbano de Bogotá en el último siglo.

Palabras clave: formación económica social, geohistoria, geografía urbana, modo de producción, sustentabilidad ambiental, territorio y sociedad.

\footnotetext{
Abstract

The research objective was to review the relationships between urban developments and urban environmental degradation that have occurred in the context of the evolution of the processes of imposition of ideological

1 Este artículo presenta resultados de la investigación Sustentabilidad ambiental en Bogotá. evolución del modo de producción, la formación económica social y el espacio urbano en Bogotá (1920-2010), realizado por el autor para optar al título de Magíster en Geografía.

2 Arq. MSc. en Geografía, Convenio Universidad Pedagógica y Tecnológica de Colombia, Instituto Geográfico Agustín Codazzi. Docente investigador Universidad La Gran Colombia. Líder del Grupo de Investigación Desarrollo Urbano Regional Sostenible (DURS). Colombia. luis.duquino@ugc.edu.co
} 
structures of domination and in everyday life issues in society. We used a qualitative methodology which allowed us to examine the relationship between the constituent parts of the object of study and the dialectical character of the reality. The result was a geo historical analysis which demonstrated the exploitation processes that have degraded the urban environment of Bogota in the last century.

Keywords: Socio-economic training, geo history, urban geography, mode of production, environmental sustainability, territory and society. 


\section{Introducción}

Las relaciones y procesos constituidos entre el modo de producción, la formación económica y social y el espacio urbano de soporte, se configuran como la materialización de un proyecto de construcción espacial (evolución urbana) y las repercusiones propias del mismo en el sistema natural de soporte (impacto ambiental), lo que tiene como resultado formal, arquitecturas sociales multiescalares y multitemporales que han venido edificando dicha realidad formal, a la vez que ellas mismas son moldeadas por estos elementos de forma recíproca, en un proceso relacional altamente dinámico y dialéctico. En este panorama se inscribió la investigación, en la cual se revisó desde la perspectiva del materialismo histórico geográfico ${ }^{3}$ (geografía crítica) y del discurso de la sustentabilidad ambiental ${ }^{4}$ (saber ambiental),

3 La idea de materialismo histórico geográfico es tomada del trabajo de David Harvey (2000), quien construye dicho discurso, en su texto, Spaces of Hope (tal como, igualmente lo identifica Ricardo Rubio en su reseña para la revista de geografía Norte Grande, del año 2003) y que tiene constante presencia en los trabajos posteriores, como Spaces of Capital. Towards a Critical Geography (2001) y The New Imperialism (2003).

4 El concepto de sustentabilidad ambiental aquí usado, tiene su origen en el trabajo de Enrique Leff, elaborado en sus libros: Ecología y Capital. Racionalidad ambiental, democracia participativa y desarrollo sustentable (1998), Saber ambiental, sustentabilidad, racionalidad, complejidad y poder (2002), Racionalidad ambiental, la reapropiación social de la naturaleza (2004) y Discursos sustentables (2008). La visión de Leff es complementada con el trabajo del geógrafo Carlos Mario Yory, representado en los tres tomos de la investigación titulada Ciudad y Sustentabilidad, a saber: I. Marco general y descripción de la problemática (2004), II. Componentes y contenido de un proyecto sustentable a partir del concepto de topofilia (2005) y III. Caracterización de la ciudad de Bogotá en el marco de sus vulnerabilidades y desafíos para la implementación de un proyecto sustentable de ciudad a partir del concepto de topofilia (2006). el proceso de evolución de la realidad urbana de la ciudad de Bogotá y su impacto en el espacio geográfico natural de soporte, durante el siglo XX y la primera década del siglo XXI. La delimitación del período histórico obedece, en principio, a la irrupción del fenómeno urbano como realidad originada en el siglo XX, sobre todo a partir de los años veinte, como resultado de los procesos de incipiente industrialización, y finaliza en la primera década del presente siglo. En resumen, el presente texto pretende constituirse en un análisis geohistórico insertado en el vasto universo de las relaciones sociedad-naturaleza, desde la óptica de la disertación de los modos de producción y reproducción del capital como aparatos de dominación vigentes en todo el período de estudio y desde la óptica del saber ambiental5, como contrapropuesta a la racionalidad economicista en la administración de los valores ambientales y en la relación misma sociedad/naturaleza.

\section{Implantación del modo de pro- ducción: capitalismo comercial ex- tractivo}

El proceso de evolución de la espacialidad de Bogotá entre 1920 y 2010, se construyó sobre las intensas transformaciones que la sociedad colombiana vivió en este período. El territorio de la ciudad es una expresión espacial de los

5 El saber ambiental está intensamente relacionado con el saber cultural y las formas del hábitat, diferenciado en cada contexto histórico asumido en el marco de una realidad geográfica, social, política y económica establecida. 
acomodamientos propios de un proceso de evolución de la formación económica social (FES), que de acuerdo con la jerarquía de los intereses de clase de los individuos, se va imponiendo en mayor o menor grado. Las ideologías como perspectivas desde las cuales la sociedad interactúa sobre el mundo, corresponden a la supraestructura que orienta los procesos de relacionamiento por medio de los cuales se constituyen las FES, definiendo el papel de cada clase y de cada individuo, en la estructura jerárquica social. Es relevante establecer que para la presente disertación, la FES se define como una categoría eminentemente marxista, en la medida en que la conformación de la realidad social a lo largo del proceso económico, tiene papel principal en el debate del materialismo histórico, es así como:

La noción de formación económico social (FES) surgió en el pensamiento marxista como una necesidad de contrarrestar las tendencias economicistas y mecanicistas, que buscaban explicar la complejidad de la organización cultural en términos de una articulación de modos de producción, fundadas en las estructuras productivas y la relaciones sociales de producción. (Leff, 1998, p. 56)

El sistema capitalista como modo de producción presente en todo el período histórico estudiado (1920-2010), fue sufriendo cambios orientados desde los espacios de poder del capital mundial, en la búsqueda de nuevas, mejores y más eficientes formas de acumulación económica. Dichos cambios en la evolución del modo de producción, se manifiestan en fases, que tuvieron énfasis de acuerdo con la actividad económica más intensamente desarrollada: comercial, industrial, financiera y de servicios6. La economía colombiana, desde sus orígenes7, incorporada en el contexto de la economía mundial, recibe la orientación de los cambios propuestos desde los centros de poder económico mundial y asume su rol en la división internacional de la producción y del trabajo, generando acomodamientos internos tendientes a organizar la estructura social, política, económica y espacial, con el fin de lograr ejecutar el papel asignado, con el mayor grado de eficiencia posible. Es así como en la fase extractiva comercial impuesta desde la llegada de los españoles al continente, desarrollada durante la colonia y mantenida hasta bien entrado el siglo XX, el papel del país se manifestó en la disposición de una economía extractiva fundamentada en el modelo agroexportador y en la explotación intensiva de materias primas para el primer mundo. La configuración espacial de este tipo de modelo económico, favoreció la concentración de la población en las áreas rurales del país, la aparición de pequeños enclaves urbanos encarga-

6 Dichas fases se refieren al acento y preponderancia de la actividad productiva que en cada momento histórico se manifiesta, teniendo presente que en cada fase las actividades de explotación anteriores siguen presentándose, pero con un rol diferente dentro de la economía del territorio estudiado.

7 Orígenes que se remontan a la mundialización del sistema de producción capitalista a partir de 1492 con el inicio del proceso de descubrimiento y saqueo del continente americano. 
dos de centralizar la institucionalidad pública y privada para la administración del modelo de explotación económica y la disposición de una incipiente infraestructura de movilidad orientada a transportar las materias primas, agrícolas y minerales, desde los espacios de la producción hacia los puertos de salida que conectaban el territorio explotado con los centros de dominio mundial. En este panorama espacial, Bogotá desempeñó un papel relevante, en la medida en que se erigió desde tempranas épocas como centro administrativo y político del territorio, concentrando la institucionalidad propia del modelo capitalista comercial, y recibiendo a su vez una serie de emprendimientos en su organización espacial, administrativa, económica y social, que fueron bases para la actuación en otras ciudades del país.

La configuración espacial en el modelo del capitalismo comercial en Colombia, fue una expresión de la organización de la FES que le corresponde, establecida, en las clases dominantes representadas por una elite local constituida por terratenientes que garantizaban su statu quo en torno al poder que les confería la tenencia de grandes extensiones de la tierra fértil y cultivable del país, y en el ejercicio de sometimiento a un campesinado explotado a través de formas semiesclavistas que garantizaron una alta eficiencia económica del proceso de producción (Kalmanovitz, 1995). Las clases sociales explotadas, también fueron parte de la FES de esta fase de capitalismo comercial y estarán constituidas principalmente por el campesinado adoctrinado a través de las lógicas y la moral del catolicismo que en su implantación garantizaron la sumisión y apego a las formas tradicionales de explotación del trabajo. Otro de los segmentos de las clases explotadas, se encuentra representado por los aborígenes, antiguos habitantes hegemónicos del país, quienes serán despojados de su capacidad productiva en la medida en que son desplazados de las tierras más fértiles que ocuparon ancestralmente y relegados a espacios marginales del territorio y de la sociedad. En los pequeños poblados urbanos se encontraban los sirvientes e individuos dedicados a los servicios propios de las incipientes urbes, quienes también son parte del sector dominado de la sociedad.

\section{Situación ambiental urbana en el capitalismo comercial}

Las FES y el aparato económico de este capitalismo comercial, perfilaron una serie de impactos ambientales, propios de sus formas de explotación de los recursos naturales, de los modos de ocupación espacial y de los hábitos de las sociedades construidos sobre su imaginario cultural y simbólico (europeo) que se impuso al imaginario preexistente (indígena). Es así como el impacto ambiental de la fase capitalista comercial se expresó en una explotación avasallante de los recursos naturales presentes, fundamentada en la sensación de abundancia infinita que se construyó sobre el imaginario de los conquistadores y colonizadores, desde el cual se visualizó 
la gran exuberancia del espacio geográfico colombiano y su rica biodiversidad, como un impedimento para el progreso, en la medida en que este espacio salvaje, malsano e inhóspito debía ser civilizado por las nuevas lógicas impuestas. La devastación de la biodiversidad presente en el país se desarrolló a través de procedimientos que requirieron del uso de una violencia desmesurada sobre la naturaleza y las sociedades preexistentes en el territorio colombiano. Dicha violencia dejó un rastro indeleble en la historia del país, marcando de forma determinante el destino de la nación y haciendo presencia constante en las fases subsiguientes de desarrollo histórico. De igual forma, el proceso de devastación de las selvas del país, reconfiguró la especialidad geográfica, reacomodando el territorio a las nuevas actividades de explotación económica; en especial la agricultura (de productos demandados desde los centros de poder del capital) y la ganadería extensiva. La ocupación fragmentada y expandida del territorio bajo el modelo rural, no generó en principio afectaciones ambientales propias de las concentraciones extensivas de población, pero desde momentos tempranos las pocas áreas del país con densidades mayores, como las incipientes ciudades, generaron problemáticas ambientales asociadas a la contaminación y degradación del espacio geográfico natural de su entorno inmediato, avaladas de igual forma desde el imaginario de la abundancia y el menosprecio por los valores ambientales. Por lo tanto, el impacto ambiental para esta época en Bogotá, estuvo manifestado en el consumo de los recursos naturales más cercanos para mantener el enclave y en la contaminación y degradación de los valores ambientales contenidos en el propio límite de la ciudad, a través del desarrollo cotidiano de la vida de sus ciudadanos.

Bajo esta etapa de una economía extractiva con énfasis en lo comercial, se escenifica la relación ser humano/naturaleza en el espacio geográfico de Bogotá, relación que da como resultado una situación de insustentabilidad ambiental, en la medida en que los derroteros que la orientaban para la época (entre el siglo XVI y el XIX) se encontraban cifrados en lógicas de explotación intensa de los recursos naturales presentes en el territorio, que se caracterizan por la ausencia de cualquier consideración que incluya la incorporación del saber y las potencialidades contenidas en el universo de lo ambiental.

\section{Capitalismo industrial}

Con la revolución industrial y las nuevas formas de producción basadas en el fordismo, la manufactura de mercancías tomará el papel principal de la producción económica mundial, generando de igual forma nuevas expresiones sociales y espaciales, más afines con dichos modos de explotación económica. En el paisaje social, nuevos actores irrumpen; en el caso de los sectores dominantes de la sociedad colombiana, las elites conformadas por las nuevas burguesías comerciales, financieras e industriales, 
lentamente ocuparán el espectro anteriormente monopolizado por los terratenientes. Estas nuevas burguesías asumieron el propósito de la modernización del país como condición sine qua non, para los emprendimientos de industrialización de la economía local. Bajo los preceptos de dicha modernización, lo que pretendieron las nuevas burguesías locales, fue la inserción del país al nuevo clima mundial de la producción industrial (Ocampo, 2007). Los procesos de industrialización de principios de siglo $\mathrm{XX}$ en Colombia, se vieron impulsados además, por los períodos de crisis experimentados desde los centros de poder mundial: la Primera Guerra Mundial (1914-1918), el crash de 1929 y la Segunda Guerra Mundial (1939-1945), durante los cuales el flujo de las mercancías manufacturadas desde los centros de producción industrial del primer mundo se interrumpen, y los mercados de la exportación agrícola y de materias primas se restringen, condiciones que coadyuvaron a la dinamización de la producción manufacturera nacional en el proceso conocido como de sustitución de importaciones (Ocampo, 2007).

El proceso de industrialización del país significó un reacomodamiento de la disposición y el ordenamiento del territorio. La necesidad de concentrar la población cerca de los nuevos polos de desarrollo industrial localizados en las ciudades, generó el fenómeno de urbanización acelerada del país, nutriendo la migración campo/ciudad, que ya se venía escenificando impulsada por la situación de violencia, principalmente rural, en Colombia. La ciudad se convierte en el espacio paradigmático del nuevo modelo de explotación capitalista, espacio de expresión de las transformaciones sociales en curso y escenario de la modernización impulsada desde las elites locales. Las burguesías industriales expresaron nuevos deseos y necesidades de clase, orientados a imitar los modelos culturales y de comportamiento de las elites del primer mundo, en un proceso de mímesis bajo el cual configuraron su visión de identidad. Esta situación acarreó una serie de transformaciones en el hábitat local que reconfiguraron el territorio, generando emprendimientos urbanísticos y arquitectónicos que escenificaron en la ciudad paisajes imitados de modelos urbanos extranjeros, los cuales convivirán en contradicción con la especialidad propia de la situación premoderna y de precariedad económica de la ciudad (Del Castillo, 2003). Contradicción espacial, complementada con la contradicción social expresada en la convivencia de clases distanciadas por grandes brechas económicas sustentadas desde la posición de cada grupo social en el proceso de acumulación material, lo que a su vez se materializa espacialmente en la marginalización de los barrios obreros (Figura 1) inicialmente (Amézquita, 2007).

Bogotá, como principal ciudad de la nación, vivió estos procesos intensamente, gran parte de los flujos migratorios del campo a la ciudad que se presentaron en el país, tuvieron como destino la capital, acrecentando problemáticas asociadas a una rápida y caótica transformación de la espacialidad de la ciudad de princi- 
pios de siglo $\mathrm{XX}^{8}$. La ausencia de una institucionalidad fuerte que arbitre los complejos choques de intereses entre lo privado y lo público (Suárez, 2006), la baja capacidad del Estado para proveer servicios públicos, la imposibilidad estatal de proveer nuevas áreas residenciales para ofertar vivienda digna, la ausencia de una estructura vial acorde con las nuevas demandas de movilidad y la deficiencia de espacios para la provisión de servicios sociales (hospitales, escuelas, universidades y espacios culturales), fueron las características que definieron desde un principio el caos manifiesto de Bogotá.

Las masas campesinas desplazas y atraídas al espacio urbano de Bogotá, sufrieron un proceso de adaptación forzado y violento a las circunstancias de una espacialidad ajena a su medio rural. Las condiciones de hacinamiento e insalubridad fueron constantes en los espacios ocupados por los campesinos en tránsito a ciudadanos urbanos, condiciones que sumadas a su posición de relegados de los procesos de acumulación económica en curso, a la imposibilidad de encontrar representación de sus intereses en los espacios de poder y a la represión, persecución y violencia estatal y paraestatal de la que fueron víctimas constantes, construyeron el contexto para originar una insalvable brecha socioeconómica y el descontento social en aumento que encontró con posterioridad una expresión violenta a modo de respuesta (Kalmanovitz, 2010).

La radicalidad de la segregación socioe-

8 Espacialidad más cercana a un pueblo grande que a una ciudad. conómica desde las tempranas épocas de configuración de la realidad urbana de Bogotá, tuvo su manifestación espacial; la segregación espacial fue desde el principio un instrumento de ordenamiento de la ciudad. El desplazamiento e implantación de las áreas residenciales de las clases menos favorecidas, fue inicialmente establecida, desde los espacios de poder local, en los sectores del territorio bogotano menos aptos para la vida humana, de menor calidad espacial y ambiental, con mayores riesgos a desastres naturales y con menor potencial de localización estratégica. En contraposición, los espacios con mejores condiciones ambientales y de localización, fueron reservados para la vivienda y las actividades de las elites locales. En un temprano hecho de la historia de la ciudad, puede observarse este planteamiento: el desplazamiento de los indígenas del resguardo de Usaquén, que habitaban los territorios al norte de la ciudad colonial, los cuales fueron desalojados hacia Bosa y Soacha, a terrenos menos apetecidos por los terratenientes locales (Martínez, 1983). De allí en adelante una y otra vez hasta el día de hoy, se han desplazado las poblaciones menos favorecidas de los territorios de mayor calidad espacial o estratégica, con el objetivo de garantizar la consolidación de áreas por ocupar por parte de las elites locales empoderadas en los gobiernos de turno. La segregación socioespacial se institucionalizó desde un principio a través de la normatividad asociada a la planeación urbana. Normatividad que designó las áreas para la vivienda obrera y proletaria ${ }^{9}$, en los sectores de la

9 Ver Acuerdo 74 de 1925, Bogotá Futuro, y Acuerdo 21 de 1944, Plan Soto Bateman (Saldarriaga, 2000). 
ciudad de menor calidad espacial, localizados principalmente en el sur y el occidente de Bogotá (Figura 1). De igual forma, la segregación socioespacial se vio manifestada en las intervenciones de infraestructura pública urbana, de las cuales fueron intencionalmente más favorecidas las zonas que alojaban las elites locales. Las masas de migrantes campesinos llegados a la ciudad, tuvieron que ocupar los espacios marginales de la ciudad, generando capa tras capa de cinturones de miseria en los "extramuros" de Bogotá para cada momento histórico. La situación de explosión demográfica y crecimiento urbano desbordado, vivida con mayor acento en las décadas del cuarenta, cincuenta y sesenta del siglo XX, no puedo ser sorteada desde el débil aparato institucional, por tanto las condiciones de habitabilidad de los nuevos ciudadanos urbanos fueron cada vez más difíciles, generando una ciudad desordenada y desarticulada, donde vienen conviviendo en alta contradicción los estándares más altos de la modernidad con las condiciones más paupérrimas del atraso.

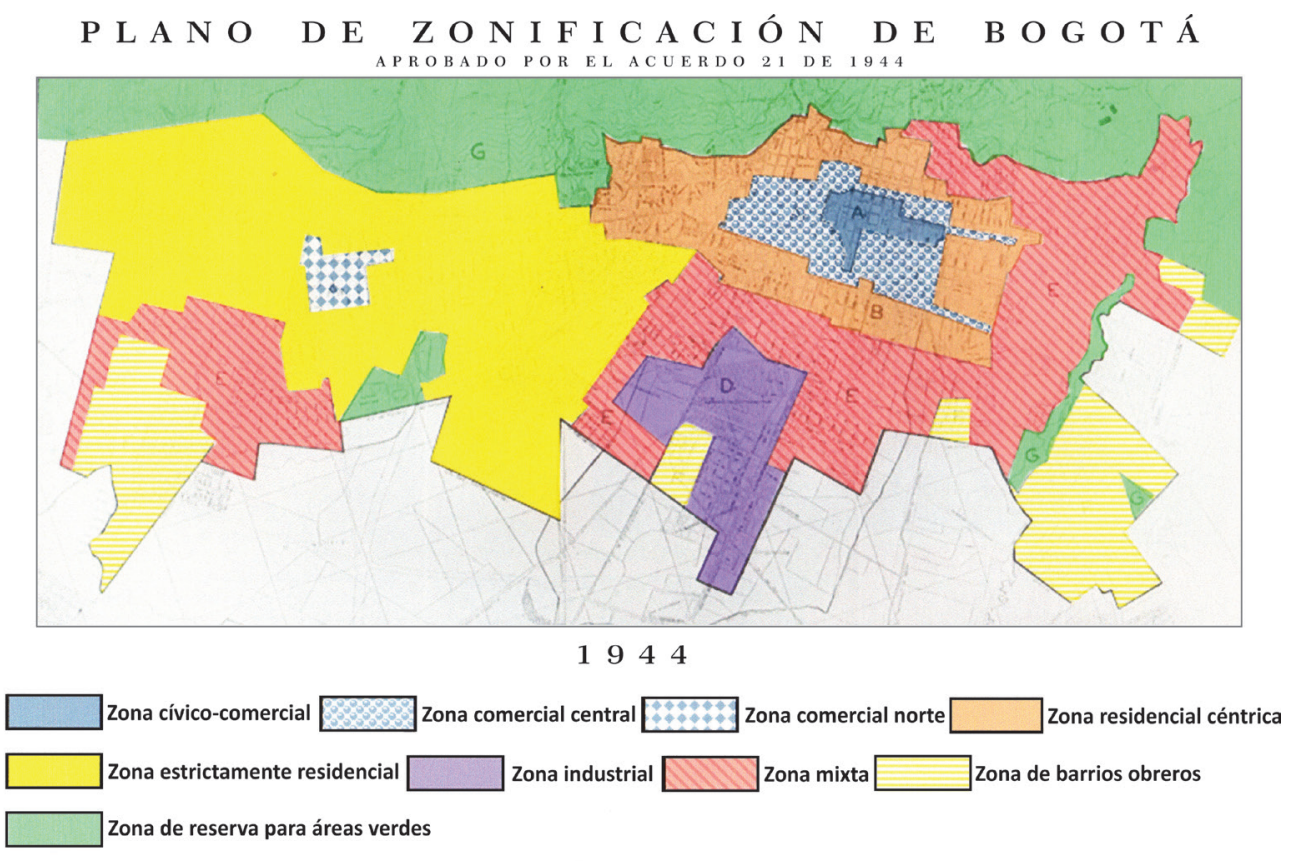

Figura 1. Plan Soto Bateman, zonificación, 1944.

Fuente: tomado de Vargas (1987, p. 95), intervenido por el autor.

La industrialización de la economía colombiana y bogotana, se fue manifestando en la organización de la ciudad para cumplir su papel de espacio más adecuado para el desarrollo de las actividades económicas asociadas a la producción 
industrial. La complejización propia del crecimiento intenso de la sociedad, fue manifestándose en la complejización del gobierno de la ciudad, de las actividades que tienen asiento en esta y de los instrumentos de planificación urbana; todos estos elementos fueron siempre un paso atrás, a menor velocidad que la de los fenómenos en curso, generando un constante atraso en todos los intentos de solución a las problemáticas urbanas.

\section{Situación ambiental urbana en el capitalismo industrial}

Los impactos ambientales de este período de ciudad industrial, se manifestaron en las condiciones de sobrepresión que recibieron los recursos naturales presentes tanto en el interior del espacio urbano, como en la región geográfica de la que se servía la ciudad de Bogotá. El intenso crecimiento de la población bogotana entre 1950 y 1970, fue consolidando una alta densidad urbana solucionada espacialmente a través de un modelo de ciudad densa y compacta, situación que generó un impacto ambiental cada vez más complejo, expresado en:

- Un aumento en el consumo de agua urbano, por el cual se debió incluir el uso de fuentes hídricas regionales para el suministro de Bogotá, sobreexigiendo los caudales de diversas hoyas hidrográficas, ampliando la escala del impacto ambiental a la región.
- La constante contaminación de las redes hídricas que discurrían por el espacio urbano, fruto de la desorganización de los sistemas de alcantarillado, de intensos procesos de vertido de contaminantes originados en las actividades residenciales, industriales y demás que tienen asiento en la ciudad.

- La edificación acelerada de la ciudad generó grandes demandas de materiales de construcción, muchos de los cuales fueron explotados en el propio territorio de Bogotá; las canteras de arenas y material pétreo ubicadas en los cerros orientales en el sur y el norte de la ciudad, los chircales para la producción de ladrillo concentrados en las laderas surorientales de los cerros, la explotación de gravilla en los lechos de los ríos, como el Tunjuelo. Estas explotaciones no reguladas ni vigiladas adecuadamente por la estructura institucional de la ciudad, generaron grandes impactos ambientales sobre los valores ambientales presentes en el territorio, manifestados en la devastación de áreas arboladas, en el daño a la red hídrica y en la erosión de suelos. Sobre algunos de estos territorios, luego de abandonada la explotación de la cantera, se constituyen los barrios por autoconstrucción de origen informal, caracterizados por su deficiente calidad urbanística y por la problemática de riesgo de remoción en masa de dichas áreas.

- El desecamiento de la red de humedales de la ciudad, con el fin de ganar nuevas áreas de urbanización para la 
ciudad, que generó un desbalance de la red hídrica urbana, haciendo más vulnerable el territorio de la ciudad a inundaciones y perdiendo la riqueza en biodiversidad de las redes de humedales, quebradas y ríos de Bogotá.

- La presión por nuevo suelo soportada en los acelerados procesos de crecimiento poblacional, impulsó el cambio de uso del suelo a terrenos que tenían grandes potenciales para el uso agrícola, relegándolos al uso urbano, con lo cual se perdió un gran potencial, aprovechable para garantizar la seguridad alimentaria de la ciudad misma.

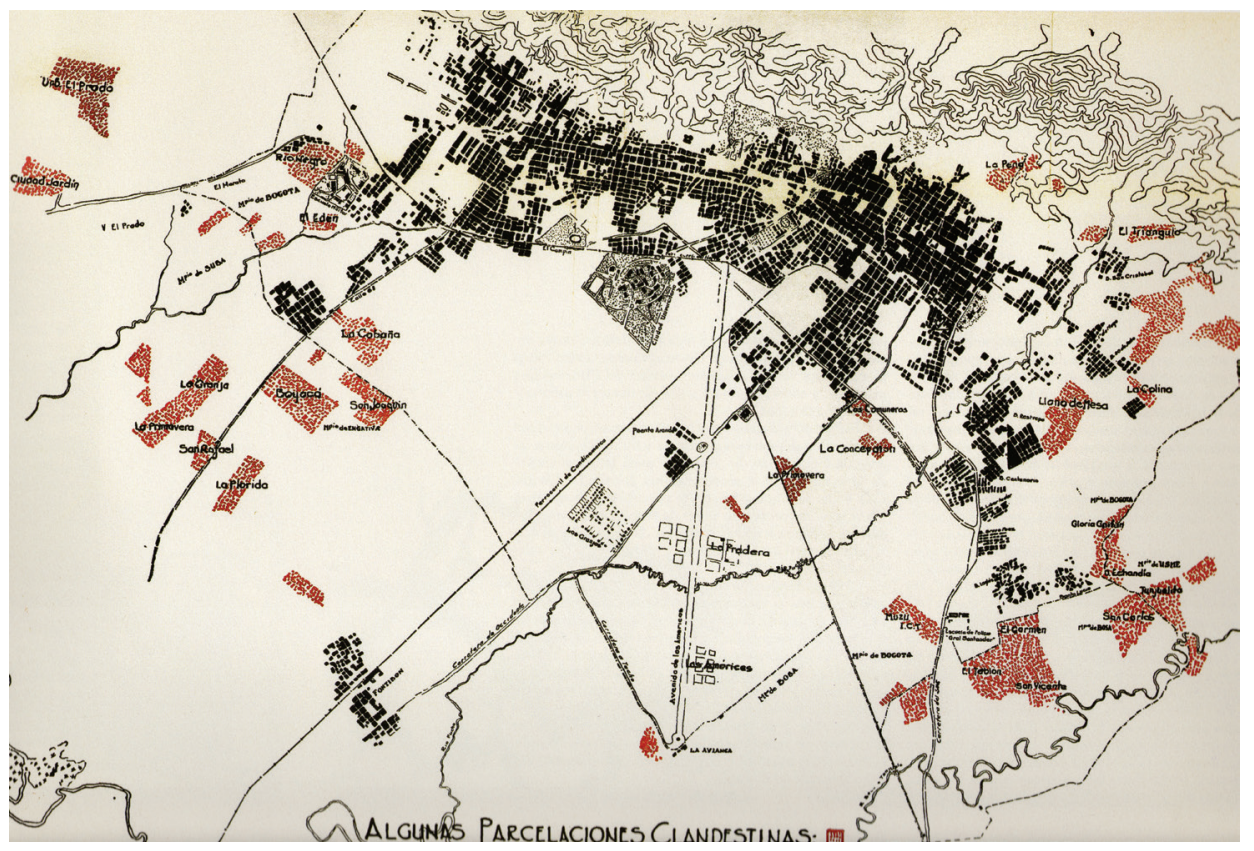

Figura 2. Croquis sobre urbanizaciones clandestinas (en color rojo), 1950 Fuente: tomado de Cuellar y Mejía (2007, p. 109).

La condición de insustentabilidad ambiental de la ciudad, se mantuvo presente en esta etapa de capitalismo en su fase industrial, radicalizándose en la medida en que dicho modo de producción aportó nuevas formas de afectación ambiental del espacio geográfico de la ciudad, asociadas a la presión que sobre el territorio generó la concentración creciente de población propia del modelo urbano-industrial. Afectación ambiental a la que se sumó la aún presente degradación del modelo extractivo agrícola, la cual se fue sofisticando bajo la implementación paulatina de algún grado de tecnificación en el campo y en la explotación minera. 


\section{Capitalismo financiero $y$ de servicios}

Finalmente, en el período más reciente de desarrollo de la ciudad, bajo la aparición de las políticas neoliberales y los discursos de la globalización, Bogotá ha venido transformándose espacialmente al ritmo de los acomodamientos propios de estos cambios de orientación política, económica y social. La industrialización como política nacional fue perdiendo relevancia en el contexto de la crisis del capitalismo mundial de 1973, comen- zando a manifestarse una desaceleración en este renglón de la economía, el cual se había mantenido en constante crecimiento desde la década de los treinta. La pérdida de fuerza de la industrialización se manifestó, entre otras, en la disminución de establecimientos dedicados a esta actividad, lo cual fue liberando espacios que anteriormente estaban dedicados a la actividad manufacturera y que requirieron operaciones de renovación para entregarlos a actividades mucho más rentables en el contexto económico.

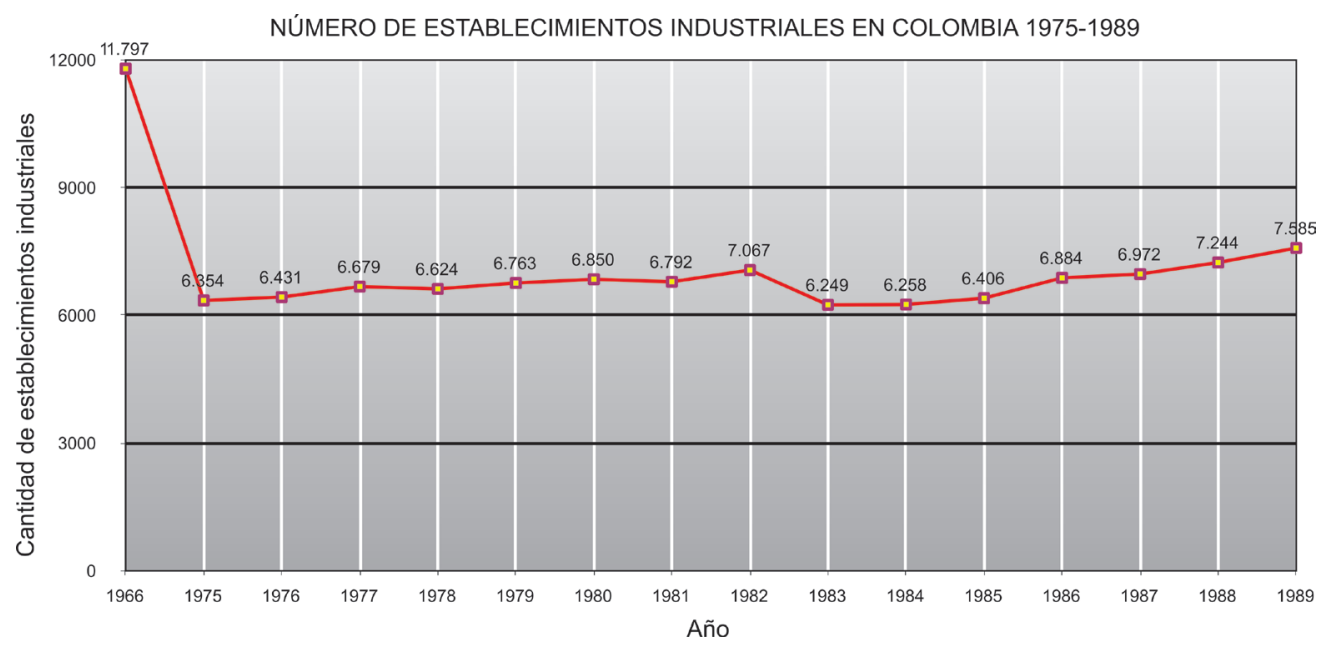

Figura 3. Establecimientos industriales en Colombia 1975-1989

Fuente: DANE (2011).

La irrupción de las actividades terciarias en la economía mundial, se escenificó de igual forma en la economía colombiana y bogotana, dando paso a la preponderancia económica de las actividades financieras, comerciales y de servicios, con acento en las telecomunicaciones, el turismo y las tecnologías asociadas a la computación (Harvey, 2009). La sociedad industrial mundial transitó en la transformación hacia la consolidación de una sociedad informacional, desde la década de los setenta, donde la conectividad virtual, el acortamiento de las distancias por el acelerado desarrollo de los medios de transporte y el rompimiento de todas las barreras proteccionistas para el flujo libre de los capita- 
les de inversión mundial, han sido las características fundamentales que han orientado los modelos políticos, económicos y sociales que se han impuesto desde los centros de poder mundial. La ortodoxia del discurso neoliberal se impuso en la economía colombiana a partir de los adoctrinamientos del Consenso de Washington, que tuvieron como resultado la imposición de un plan de desarrollo nacional orientado a la apertura económica, a la desregulación de la actividad económica, a la privatización de los negocios estatales, a la flexibilización del mercado laboral y, en general, a un retroceso marcado de la esfera de influencia del Estado en el manejo del país; la revolución pacífica del presidente Gaviria en 1990 (DNP, 1991).

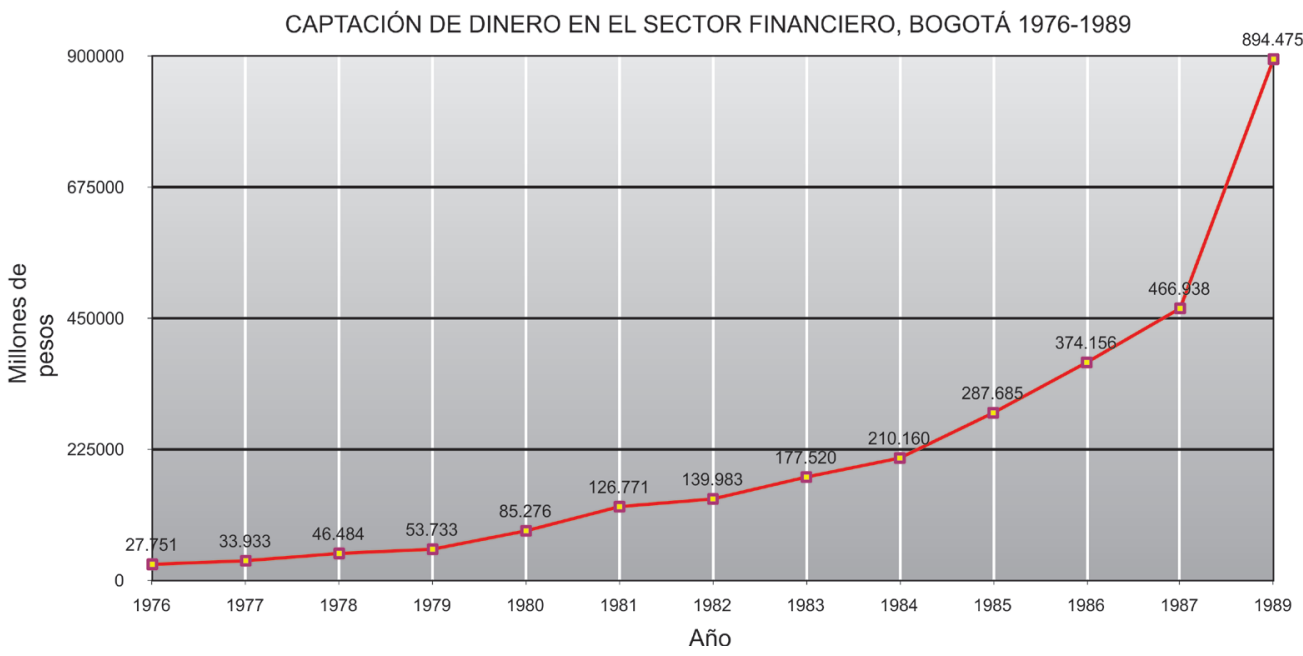

Figura 4. Captación de dinero entidades financieras, Bogotá 1976-1989.

Fuente: DAPD (2000, p. 65).

Los resultados de este tipo de doctrina son bien conocidos; ruina en la actividad agrícola nacional, desaparición paulatina de la actividad industrial, inundación del mercado local de mercancías extranjeras, disminución del empleo formal a favor del fortalecimiento del empleo informal, desaparición paulatina de la administración de los servicios públicos por parte del Estado que da paso a la imposición de monopolios transnacionales para el manejo de estos servicios, desmonte de los mecanismos de protección que existían sobre el empleo para dar paso a una sobreexplotación de la mano de obra y dependencia cada vez más severa del endeudamiento público y de las economías del primer mundo, para garantizar algún nivel de crecimiento económico (Kalmanovitz, 2010). Las transformaciones económicas tuvieron, a su vez, manifestaciones sociales que, a su vez, tienen una expresión espacial. Las brechas de inequidad social aumentaron en la medida en que los pocos mecanismos de protección del empleo y 
de las actividades productivas del país fueron cayendo bajo las indicaciones de las lógicas neoliberales, aumentando la marginalidad y la segregación socioespacial en el país y en Bogotá. Segregación construida a través de la aparición de nuevas lógicas para ocupar el territorio. Desde la década de los setenta se ha venido imponiendo la forma de urbanización conocida como "conjunto cerrado", la cual se ha instituido como la forma de habitar preferida por las clases sociales medias y altas de la sociedad bogotana.

El cerramiento materializado a través de la aparición de muros, rejas y porterías, ha generado nuevas lógicas de ocupación del espacio urbano, cortando el flujo de la vida urbana e interrumpiendo el libre tránsito y goce de la ciudad. El retroceso de la presencia estatal en la administración de la "seguridad policiva" de la ciudad, se manifestó en la aparición de la "seguridad privada", que administra y selecciona los flujos de los individuos en los espacios urbanos privados y públicos, pues no solo en las áreas residenciales se impone la vigilancia de quién entra y quién sale, sino también en el espacio público, sobre todo de los territorios ocupados de la elite privilegiada local, en los cuales aparece la imposición de controles sociales expresados a través de la reserva del "derecho de admisión" de los marginales, contrariando el espíritu propio de estas áreas que en su propia definición deben estar abiertas para el goce indiferenciado de los ciudadanos. El espacio público bogotano también ha sido escenario de los acomodamientos a las nuevas condiciones económicas y sociales. El sector informal en crecimiento de la economía local, se ha manifestado con fuerza en la venta ambulante como única posibilidad de sustento para grandes masas de desposeídos, dentro de los cuales se encuentran los tradicionales mendigos, indigentes, desplazados rurales por la violencia y vendedores de toda clase de mercancías y "baratijas" que desde los espacios de producción intensificada mundial, inundan las calles bogotanas y de las principales ciudades del país.

El paisaje social del espacio público se complementa con la aparición de actividades ilícitas sobre éste, asociadas al auge del mercado de los alucinógenos (sustancias psicoactivas) y al cierre paulatino de las posibilidades laborales dignas en la ciudad, a la escasez de oportunidades de formación académica y a la informalización de la economía, situaciones que coadyuvan la consolidación del hampa organizada, el pandillismo y la prostitución; actividades que escenifican dicho espacio público de la ciudad. La explotación económica del espacio público contrasta con los proyectos sobre estos mismos espacios que se orientan desde la administración pública de la ciudad, los cuales se diseñan desde los criterios calcados de las propuestas del primer mundo, ignorando la realidad socioeconómica local, generando contradicción entre lo que se impone y lo que se vivencia realmente en la ciudad. La actividad comercial y de servicios que fue ganando terreno por sobre todos 
los demás renglones de la economía nacional, también ha venido dejando una huella en la espacialidad de la ciudad. La construcción de los centros comerciales de la ciudad, las nuevas "catedrales del consumo", ha mantenido un ímpetu vigoroso impactando el paisaje urbano y social de Bogotá. El modelo de centro comercial bogotano copiado del "shopping mall" norteamericano, va desplazando al espacio público (la calle, la plaza y el parque) como espacio de encuentro y de recreo de la sociedad bogotana. El auge de este tipo de construcción es bien notorio; los cuatro más grandes y recientes centros comerciales de la ciudad ${ }^{10}$ suman entre sí más de un millón de metros cuadrados de área construida, erigiéndose como un espacio paradigmático de la Bogotá de las últimas tres décadas (donde, al igual que en los conjuntos residenciales, es reservado el derecho de admisión). En términos de áreas residenciales, las elites locales que no se autoexiliaron en el exterior, siguieron construyendo una espacialidad en la ciudad, lo más aislada posible de los marginales y de los "indeseables", espacialidad orientada por los estilos de vida basados en los modelos norteamericanos y europeos ${ }^{11}$. Espacialidad autosegregada mediante la aparición de cada vez más distantes urbanizaciones, de acceso controlado y carácter suburbano. Los municipios colindantes al norte de Bogotá, han venido experi-

10 Centro comercial Santafé, Centro Mayor, Titán y Gran Estación.

11 Nótese la inundación de ofertas de vivienda tipo "Loft" en el mercado inmobiliario bogotano, entre otros ejemplos de apropiación del imaginario norteamericano por parte de las clases altas y medias que habitan la ciudad. mentando un fuerte crecimiento en las últimas tres décadas, a través de los emprendimientos por construir vivienda suburbana para las clases más acomodadas de la ciudad. La fuerte presión por ocupar áreas de calidad ambiental distantes del caos propio del casco urbano denso y compacto de Bogotá, ha generado el consumo y ocupación de territorios con suelos que alojan potencialidades agrícolas, paisajistas y de reserva natural, que chocan en contradicción con su destinación residencial suburbana. De igual forma, la oferta de espacios de hábitat y trabajo para las clases acomodadas de la ciudad, se ha venido construyendo en el interés constante por volver a ocupar el centro tradicional de Bogotá. La posibilidad de asentarse en un lugar estratégico de la ciudad como lo es el centro, que acumula una gran oferta de servicios urbanos: culturales, sociales, y de infraestructura, ha generado la intención de nuevos emprendimientos inmobiliarios asociados a la renovación urbana.

Con el fin de reconquistar territorios abandonados por las elites en el proceso de evolución de la ciudad, el negocio inmobiliario a través de los planes de renovación urbana ${ }^{12}$ ha cifrado su intención de explotar el suelo del centro, des-

12 Los primeros planes de renovación se remontan a la década del sesenta con la intervención en la zona conocida como Centro Internacional, un proyecto de oficinas y comercio en una antigua área residencial que para la época estaba habitada por segmentos de población pobre, en inquilinatos. Para finales del siglo pasado y principios del presente siglo, a través del Plan de Ordenamiento Territorial de Bogotá, se ha pretendido revitalizar los proyectos de renovación, pero el momento del negocio inmobiliario y la ineficiencia pública para promover estos procesos no ha permitido un avance real en esta temática. 
plazando las comunidades tradicionales, comunidades afianzadas de desplazados o de trabajadores de diversas artes liberales y virtuales que han ido rodeando los centros de decisión política del país y que se constituyen en una amenaza para las institucionalidad del sistema de dominación, en la medida en que son actores marginales sobre los cuales el ejercicio del control se hace más difícil. Ante esta situación, el gobierno de la ciudad ha fungido como facilitador de estos emprendimientos inmobiliarios en el centro de Bogotá, desde su característica ontológica de haber sido fundado como un espacio de defensa del interés privado por encima del interés público. La actividad estatal se ha resumido en la adopción del Plan Zonal del Centro (Decreto 492 de 2007), bajo el cual se gestionan las políticas de explotación del suelo, ampliamente favorables al negocio inmobiliario y que apenas contempla la problemática social de desplazamiento de los habitantes tradicionales y de la diseminación en otros espacios marginales de la ciudad de las precarias condiciones socioeconómicas que se alojan desde tiempo atrás en el centro tradicional de Bogotá. Por otro lado, las clases sociales con menos recursos, tienen acceso a una oferta de vivienda escasa, localizada en sectores de la ciudad con baja accesibilidad, en áreas con calidades urbanísticas y ambientales deficientes. Los sectores en extremo marginales de la sociedad, solo tienen acceso a los cinturones de miseria de la ciudad, caracterizados por ser zonas altamente vulnerables ante los desastres naturales, de pésimas condiciones am- bientales, en muy malas condiciones de accesibilidad y con baja oferta de servicios públicos, de servicios sociales y de espacio público. Es así como se escenifica la alta brecha social establecida desde los procesos de segregación de principio de siglo en la ciudad y que se mantiene hasta la actualidad.

La planificación urbana de Bogotá, ha mantenido hasta la actualidad los sesgos que la han caracterizado desde los primeros ejercicios que en este sentido se ejecutaron a principios del siglo XX. Características como la adopción irrestricta de los modelos urbanos foráneos, de las técnicas prospectivas urbanas de las ciudades del primer mundo y de las retoricas y los adoctrinamientos desde las entidades transnacionales como el Banco Interamericano de Desarrollo (BID) y el Banco Mundial (BM), son las que han construido el ejercicio de ordenamiento urbano en la ciudad. Dicha banca multilateral propicia la deuda externa y diseña las políticas de control geopolítico mundial; con su accionar financiero, estos bancos se convierten en impulsores de la organización del espacio urbano y promotores de las condiciones ambientales actuales, que produce la economía de mercado inundando las ciudades o saqueando recursos biológicos y geológicos. Estos agentes enunciados (BID y BM), entre otros, se involucran en el ordenamiento espacial de la ciudad, para facilitar el acomodamiento de la misma a los procesos de acumulación del capital internacional, presionando la ejecución de políticas favorables a sus intereses, a través de los flujos de en- 
deudamiento que administran. Por tanto, el resultado del ejercicio de ordenamiento y planificación de la ciudad, no es otro que el favorecimiento a la acumulación de capital internacional, permitiendo abrir espacios llamativos para la inversión especulativa y financiera de las economías del primer mundo, que a través de procesos tan agresivos como el de la acumulación por desposesión, se hacen a las potencialidades económicas de la ciudad, dejando a su paso una estela de expolio mucho mayor que los exiguos beneficios locales concedidos (Harvey, 2007). Por otro lado, la institucionalidad presente en la ciudad sigue manteniéndose a la retaguardia de las problemáticas urbanas existentes en Bogotá. Un ejemplo claro de esta situación se establece en los proyectos de movilidad para la ciudad. Existe un gran atraso en la mencionada temática de movilidad y se fundamenta históricamente en la pérdida por parte del Estado de la administración del transporte como un servicio público, experimentada durante la liquidación de la empresa del tranvía, a finales de la década de los cuarenta del siglo pasado (Zambrano, 2007). De igual forma, el estado de atraso en la problemática del transporte, se manifiesta en la ausencia de emprendimientos que amplíen la estructura de la malla vial arterial, haciendo que la ciudad prácticamente siga dependiendo de los mismos corredores viales que existen desde mediados del siglo pasado. Las obras para la ampliación de la malla vial arterial que en la actualidad se adelantan, únicamente incluyen obras que intentan actualizar los tradicionales co- rredores viales, y no se emprenden hasta ahora ni el diseño ni la construcción de la nueva red vial que descongestione e interconecte los nuevos desarrollos de la ciudad. Proyectos como la construcción de la Avenida Longitudinal de Occidente, han sido retrasados desde hace ya más de treinta años, haciendo que en la actualidad queden obsoletos para las nuevas problemáticas de movilidad de la ciudad.

\section{La situación ambiental urbana en el capitalismo financiero $y$ de servicios}

En la actualidad, la situación ambiental se escenifica en las degradaciones del sistema natural, que históricamente se han venido desarrollando. La red de ríos y quebradas que discurren en el espacio urbano, se encuentra en su mayoría canalizada y altamente contaminada por los desechos que a su paso le son arrojados. La normativa actual ha delimitado espacios de protección, rondas, alrededor de los cuerpos de agua urbanos, los cuales han sido constantemente invadidos por la actividad edilicia de la ciudad, que empuja a los habitantes más pobres a invadirlos, en la medida en que no se ofrecen alternativas de vivienda digna para estas clases sociales. De igual forma, los humedales de la ciudad han ido desapareciendo paulatinamente, por la presión de conseguir nuevo suelo urbano para desarrollar; incluso la administración pública llegó en los años setenta a pagar a los transportadores de escombros de la ciudad, 
para que descargaran estos desperdicios en humedales, con el fin de ampliar el área disponible para urbanizar (Zambrano, 2007). Apenas en las últimas décadas del siglo XX, la conciencia de preservación de los valores ambientales propios de los humedales de la ciudad, ha generado algún grado de protección de dichos elementos. La explotación minera orientada a la producción de materiales para la construcción, también se ha mantenido intensamente sobre el espacio de los cerros surorientales de la ciudad, caracterizándose por ser mayormente ilegal e informal, impactando de manera agresiva los valores ambientales presentes en las zonas de explotación, con una muy baja regulación e intervención estatal. Los cerros de Suba, desde la década de los sesenta del siglo pasado, han sido escenario de constantes emprendimientos urbanizadores, en un espectro amplio que abarca desde la vivienda suntuosa para las clases más acomodadas de la sociedad bogotana, pasando por la oferta de vivienda para clase media, y finalmente conteniendo una serie de barrios de origen informal, que se construyeron ilegalmente sin la provisión de servicios ni espacio público (Saldarriaga, 2000). La sobrepresión sobre el espacio de los cerros orientales, ha logrado que cada vez más se mueva la delimitación del área de protección, ampliando el impacto y la pérdida de los valores ambientales presentes en este espacio. La alta demanda de suelo urbano, que se acelera en la medida en que el espacio disponible es ocupado y las tasas de crecimiento poblacional siguen siendo altas, genera una expansión de la ciudad hacia suelos que tenían otras potencialidades de uso. Es el caso de la expansión norte, que finalmente a través de la adopción del Plan Zonal del Norte (instrumento del POT), permitirá el desarrollo de la ciudad sobre suelos altamente fértiles y de calidad ambiental, igualmente susceptibles a riesgos de inundación, perdiéndolos definitivamente ante el voraz apetito del negocio inmobiliario.

En el sur de la ciudad, el Plan Zonal de Usme permitirá la expansión de la ciudad sobre el subpáramo, ocupando suelos que en la actualidad están dedicados a la agricultura y que también mantienen algún valor ambiental. La ocupación de los extremos sur y norte de la ciudad, acrecentará las diversas problemáticas de la ciudad, como el fuerte impacto ambiental a los espacios naturales que aún sobreviven en Bogotá, o el problema de movilidad interna, impulsado por la ausencia de nuevos conectores viales eficaces para el diario tránsito de los ciudadanos en el espacio urbano. El estilo de vida actual de la mayoría de los ciudadanos bogotanos, enmarcado en el paradigma del consumo, se manifiesta como uno de los elementos de impacto ambiental presentes en la ciudad. El flujo en constante aumento de consumo de mercancías, genera grandes cantidades de desperdicios que ya han hecho que el relleno sanitario de la ciudad sea insuficiente para atender las 6.200 toneladas de basuras que diariamente produce la urbe (Zambrano, 2007). La localización de un nuevo relleno sanitario se ha convertido en un gran problema 
para la administración distrital, en la medida en que su ubicación genera un debate por parte de las comunidades que se podrían ver afectadas por su cercanía al mismo. La contaminación atmosférica, fruto del uso intensivo del automóvil y de la actividad industrial que aún tiene presencia en Bogotá, ha llegado a límites de peligro para la salubridad pública. La contaminación por ruido de igual forma es bastante alta y se focaliza principalmente sobre los corredores de movilidad más activos de la ciudad, en las cercanías de las industrias y en las inmediaciones del aeropuerto, que en la medida en que se encuentra rodeado de áreas residenciales, impacta a un amplio sector poblacional.

\section{Conclusiones}

Los niveles de degradación e impacto ambiental en Bogotá, como en muchas de las urbes más grandes del planeta, han ocasionado que la ciudad sea un lugar de marcadas condiciones negativas en términos ambientales, en perjuicio de la salud de los ciudadanos y del desarrollo y disfrute de la vida misma. De tal suerte que la condición de insustentabilidad ambiental presente desde la implantación del proyecto colonial de ocupación territorial, se ha mantenido en el tiempo y se ha radicalizado, destruyendo la posibilidad de escenificar en la ciudad modos de vida equilibrados y sustentables, y, a su vez, poniendo en riesgo el futuro del territorio y de sus habitantes. Por tanto, los planteamientos que busquen una solución profunda a las problemáticas ambientales, sociales, económicas y políticas, que se escenifican hoy en día en Bogotá, deben estar firmemente cimentados en los valores que se desprenden del entendimiento de lo ambiental y lo geográfico. Lo ambiental, en su dimensión urbana, como la naturaleza creada de un entorno que es hábitat, que se construye a través de la imposición de deseos y necesidades desde los diferentes actores sociales que se enfrentan en el espacio de la ciudad por conseguir el mejoramiento de sus condiciones de vida expresado en una mejor calidad del hábitat. Lo geográfico, a través de la manifestación del espacio social e históricamente creado, expresión dialéctica de formaciones sociales concretas, las cuales nos muestran territorios profundamente trabajados desde la dependencia y la resistencia de los pueblos, comunidades y barrios que han integrado la metrópoli bogotana. Una mirada geográfica que sólo puede proyectar en profundidad la geografía crítica, por su capacidad de realizar una síntesis holística de las complejas dinámicas que se alojan en el espacio social de la ciudad, por su disposición a enfrentar la contradicción, en vez de rehuirle, contradicción que se escenifica constantemente en medio de los flujos sociales, políticos y económicos que se desarrollan en el espacio urbano y por su estructura orientada al estudio de los ordenamientos económicos como elementos fundamentales del análisis, pues es indiscutible que en la actualidad la mayor parte de las problemáticas hasta aquí descritas tienen su origen en el manejo que desde la economía se le da a 
la administración de la vida, al dominio que se intenta imponer constantemente y a los mecanismos de control, con los cuales conservar las estructuras del statu quo, más convenientes para el sistema capitalista. El capitalismo, como sistema de dominio y control hegemónico en la actualidad, ha fundamentado su fortaleza en la gestión eficiente que ejecuta sobre la naturaleza humana, manifestada en la manipulación del deseo y el miedo, como mecanismos de empoderamiento. La liberación del ser de dicha manipulación sólo será posible a través del acercamiento a una conciencia profunda de la realidad, lograda en el rescate de los valores humanos, de los saberes ancestrales y de una lectura compleja del saber ambiental expresado en el funcionamiento solidario, armónico y neguentrópico ${ }^{13}$ de un planeta que ha mantenido durante milenios la posi-

13 El concepto de neguentropía utilizado en este texto, proviene del trabajo de Leff, quien explicita su intencionalidad para con dicho concepto "...no con el propósito de negar las leyes termodinámicas 0 estadísticas de la materia física, sino en el sentido de revertir un proceso histórico social, que fundado en la racionalidad tecnológica de explotación de los recursos, ha privilegiado un creciente proceso de transformación tecnológica de los recursos; así, ha llevado a una degradación exponencial de la energía potencial acumulada en el planeta y a la sobreexplotación y desorganización de los ecosistemas naturales, lo que ha implicado la degradación de su potencial productivo. De esta manera, una racionalidad productiva orientada por un proceso social neguentrópico, contrarrestaría esta tendencia, mediante el aprovechamiento máximo (ecológico y cultural) del proceso fotosintético, como un proceso ecosistémico de producción de orden, de materia vegetal y de energía bioquímica utilizable orientado al incremento de una productividad social para la producción de satisfactores humanos por medio de la creación de un proceso histórico de organización ecológica, diversidad cultural y complejidad productiva". (Leff, 1998, p. 255256). Por tanto, la neguentropía hace referencia a la necesidad de un equilibrio contrario a los procesos entrópicos que se han impuesto desde la racionalidad dominante. bilidad del milagro de la vida, de la vida que ha alcanzado el tópico fundamental de hacer que la materia sea consciente de sí misma, a través del ser humano. Hacer de una ciudad como Bogotá, un espacio sustentable ambientalmente, implica una transformación trascendental que arranca desde el profundo cambio de las lógicas económicas, políticas y sociales en las que se ha venido manteniendo la relación ser humano/naturaleza. La profunda crisis de civilización por la que transita el mundo actual, tiene una de sus manifestaciones en la crisis ambiental contemporánea, por tanto la sustentabilidad ambiental como solución y nueva orientación supone un cambio de paradigma, que abandone los derroteros sobre los cuales se construyeron las formas de enfrentar la realidad que generaron la crisis, y adopte nuevas estructuras de pensamiento basadas en la poderosa complejidad del saber ambiental. 


\section{Literatura Citada}

Alcaldía Mayor de Bogotá. (2007). Decreto 492. Bogotá: Imprenta Distrital.

Amézquita, A. (2007, julio). Áreas residenciales en Bogotá. Barrios obreros bogotanos. Urbanismos (2), 93-103.

Cuellar, M. \& Mejía, G. (2007). Atlas histórico de Bogotá, cartografía 1791-2007. Bogotá: Planeta.

DAPD. (2000). Estadísticas históricas Santa Fe de Bogotá D.C. 1950-1999. Bogotá: Alcaldía Mayor.

Del Castillo, J. C. (2003). Bogotá. El tránsito a la ciudad moderna 1920-1950. Bogotá: Universidad Nacional de Colombia.

Departamento Nacional de Planeación. (1991). La revolución pacifica. Plan de desarrollo económico y social, 1990-1994. Bogotá: Presidencia de la República.

Harvey, D. (2003). Espacios de esperanza. Madrid: Akal.

Harvey, D. (2004). El nuevo imperialismo. Madrid: Akal.

Harvey, D. (2007). Espacios del capital. Hacia una geografía crítica. Madrid: Akal.

Harvey, D. (2009). Breve historia del neoliberalismo. Madrid: Akal.

Kalmanovitz, S. (1995). Economía y nación una breve historia de Colombia. Bogotá: Tercer Mundo.

Kalmanovitz, S. (Ed.) (2010). Nueva historia económica de Colombia. Bogotá: Fundación Universitaria de Bogotá Jorge Tadeo Lozano.

Leff, E. (1998). Ecología y capital. Racionalidad ambiental, democracia participativa y desarrollo sustentable. México: Siglo XXI.

Leff, E. (2002). Saber ambiental. Sustentabilidad, racionalidad, complejidad y poder. México: Siglo XXI.

Leff, E. (2006). Aventuras de la epistemología ambiental: de la articulación de ciencias al diálogo de saberes. México: Siglo XXI.

Leff, E. (2008). Discursos sustentables. México: Siglo XXI. 
Martínez, C. (1983). Bogotá, sinopsis sobre su evolución urbana. 1536-1900. Bogotá: Escala Fondo Editorial.

Mejía, G. (1998). Los años del cambio. Historia urbana de Bogotá 1810-1910. Bogotá: Pontificia Universidad Javeriana, Instituto de Cultura Hispánica.

Ocampo, J. A. (2007). Historia económica de Colombia. Bogotá: Planeta.

Saldarriaga, A. (2000). Bogotá siglo XX. Urbanismo, arquitectura y vida urbana. Bogotá: Departamento Administrativo de Planeación Distrital DAPD.

Suárez, A. (2006). La ciudad de los elegidos. Crecimiento urbano, jerarquización social y poder político. Bogotá (1910-1950). Bogotá: CEP, Banco de la República, Biblioteca Luis Ángel Arango.

Vargas, H. (Comp.) (1987). Le Corbusier en Colombia. Bogotá: Cementos Boyacá.

Yory, C. M. (2004). Ciudad y sustentabilidad. I. Marco general y descripción de la problemática: una aproximación crítica al concepto de desarrollo urbano sustentable orientada a las grandes metrópolis de América Latina en el contexto de la globalización. Bogotá: Universidad Piloto de Colombia, Facultad de Arquitectura.

Yory, C. M. (2005). Ciudad y sustentabilidad. II. Componentes y contenido de un proyecto sustentable de ciudad a partir del concepto de topofilia: una aproximación al contexto urbano de América Latina. Bogotá: Universidad Piloto de Colombia, Facultad de Arquitectura.

Yory, C. M. (2006). Ciudad y sustentabilidad. III. Caracterización de la ciudad de Bogotá en el marco de sus vulnerabilidades y desafios para la implementación de un proyecto sustentable de ciudad a partir del concepto de topofilia: una aproximación al tema de la planificación participativa. Bogotá: Universidad Piloto de Colombia, Facultad de Arquitectura.

Zambrano, F. (2007). Historia de Bogotá, siglo XX. Bogotá: Villegas.

Recepción: 22 de octubre de 2012

Evaluación: 15 de marzo de 2013

Aprobación: 30 de junio de 2013

302 Luis Gabriel Duquino Rojas 